Celebes Abdimas: Jurnal Pengabdian Kepada Masyarakat

http://journal.lldikti9.id/CER/index

Vol 2, No, 1, April 2020, pp 32-41

p-ISSN:2656-7938 dan e-ISSN: 2657-1870

DOI: https://doi.org/10.37541/celebesabdimas.v2i1.387

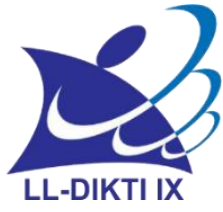

\title{
Perbanyakan Tanaman Secara Vegetatif Di Desa Pekan Kamis Kelurahan Tembilahan Barat
}

\author{
Mulono Apriyanto ${ }^{1}$, Marlina ${ }^{2}$, Muhammad Arpah ${ }^{3}$ \\ 1 Pertanian, Universitas Islam Indragiri \\ Email: mulonoapriyanto71@gmail.com \\ 2Pertanian, Universitas Islam Indragiri \\ Email: marlina@gmail.com \\ 3Pertanian, Universitas Islam Indragiri \\ Email:marpah@gmail.com
}

Artikel info

\section{Article history:}

Received: Februari-2020

Revised: Februari-2020

Accepted: Maret-2020

Publish: April-2020
Abstract. The purpose of this community service program is 1) Providing new insights to youth in youth organizations about plant propagation 2) Providing insight to youth in youth organizations about garden development 3) Youth in youth organizations can provide seeds for ornamental plants and fruit plants independent. The stages in the implementation of community service programs are divided into pre-implementation and implementation. The preimplementation stages include: 1) Field observations. 2) Stages of preparation of tools and materials. Is the preparation phase to prepare all the preparation tools and materials as training material for partners. The implementation stages include 1) Practice of making verticulture 2) Material about Propagation of ornamental plants with vegetative propagation 3) Propagation practices of fruit plants with cuttings and grafts. From the results of field observations, it is known that the problems of youth are 1) Lack of skills in park management and maintenance. The conclusion of this community service activity is that it has been able to solve the problem 1) the youth in the youth cadets are skilled in providing ornamental plant material and fruit for planting in the environment 2) the youth in the youth cadets are skilled in making a vertical garden.

Abstrak. Tujuan dari program pengabdian masyarakat ini adalah 1) Memberikan wawasan baru kepada para pemuda dalam karang taruna tentang perbanyakan tanaman 2) Memberikan wawasan kepada para pemuda dalam karang taruna tentang pembuatan taman 3) Pemuda dalam karang taruna bisa melakukan penyedian bibit tanaman hias dan tanaman buah secara mandiri. Tahapan dalam pelaksanaan program pengabdian kepada masyarakat ini dibagi menjadi pra pelaksanaan dan pelaksanaan. Tahapan prapelaksanaan meliputi : 1) Observasi lapangan. 2) Tahapan persiapan alat dan bahan. Merupakan tahapan persiapan untuk menyiapkan segala persiapan alat dan bahan sebagai bahan praktek pelatihan untuk mitra. Adapun tahapan pelaksaan meliputi 1) Praktek pembuatan verticulture 2) Materi tentang Perbanyakan tanaman hias dengan perbanyakan vegetatif 3) Praktek 
perbanyakan tanaman buah dengan stek, cangkok dan grafting. Dari hasil observasi lapangan, diketahui permasalahan dari karang taruna adalah 1) Kurangnya skill dalam manajemen pengelolaan dan perawatan taman. Kesimpulan dari kegiatan pengabdian masyarakat ini yaitu sudah dapat menyelesaikan permasalahan 1) pemuda dalam karang taruna terampil dalam penyediaan bahan tanam tanaman hias dan buah untuk di tanam di lingkungan 2) pemuda dalam karang taru terampil dalam nembuat vertical garden.

\author{
Keywords: \\ Tanaman; \\ Vegetatif; \\ Taman;
}

Coresponden author:

Mulono Apriyanto

Pertanian, Universitas Islam Indragiri, Indonesia Email: mulonoapriyanto71@gmail.com

artikel dengan akses terbuka dibawah lisensi CC BY -4.0

\section{PENDAHULUAN}

Salah satu sumber daya yang sering menjadi permasalahan yaitu sumber daya manusia, yang berhubungan erat dengan kualitas manusia yang pada dasarnya sumber daya manusia itu adalah bagian dan generasi muda. Karena generasi muda inilah yang akan kelak meneruskan tongkat estafet kepemimpinan dimasa yang akan datang, sehingga kita membutuhkan generasi yang terampil, berakhlak, bermoral serta cinta tanah air dan dapat diandalkan di tengah masyarakat terutama bangsa dan negara (Kurniasari et al. 2014).

Pertanian merupakan sektor yang sangat penting bagi masyarakat Indonesia. Sektor pertanian sebagai sumber penghasilan bagi beberapa masyarakat, karena sebagian besar kawasan Indonesia merupakan lahan pertanian. Para petani biasanya menggunakan tanah untuk media (Roidah., 2014). Meningkatnya pendidikan, pengetahuan, dan kesadaran masyarakan akan keamanan pangan, menyebabkan tuntutan masyarakat akan pangan sehat, aman dan bergizi terus meningkat. Akulturasi antarawarga perumahan dan masyarakat setempat juga meningkatkan pemahaman akan pangan sehat, aman dan bergizi. Hal tersebut mengisyaratkan bahwa peningkatan produksi pertanian harus diikuti dengan meningkatnya kualitas pangan yang aman, sehat, dan bergizi (Suyadi and Nugroho 2017). Lahan pertanian yang sudah berubah fungsi menjadi lahan pemukiman bila dikelola dengan dengan cermat maka akan dapat berdayaguna dan berhasilguna. Daerah-daerah di luar Propinsi Riau seperti di Pulau Jawa keberhasilan memberdayakan pekarangan bisa dijadikan teladan untuk dikembangkan di Pekanbaru. Pemukiman baru yang dibangun pada umumnya memiliki pekarangan yang sempit, dan pekarangan sempit inilah yang menjadi tujuan ekploitasi, sehingga dapat bermanfaat dalam menopang kebutuhan pangan keluarga (Surtinah., 2018).

Karang Taruna adalah suatu organisasi Kepemudaan yang ada diIndonesia dan merupakan sebuah wadah tempat pengembangan jiwa sosial generasi muda, Karang Taruna tumbuh atas kesadaran dan rasa tanggungjawab sosial dari masyarakat dan untuk masyarakat itu sendiri khususnya generasi muda yang ada di suatu wilayah desa, kelurahan atau komunitas sosial yang sederajat, terutama bergerak pada bidang-bidang kesejahteraan sosial (Sunoto and Nulhakim 2017). Karang Taruna merupakan salah satu organisasi sosial kemasyarakatan yang diakui keberadaannya dalam penyelenggaraan kesejahteraan sosial sebagaimana tercantum dalam Pasal 38 ayat (1-3), Bab VII tentang Peran Masyarakat Undang-Undang Nomor 11 Tahun 2009 tentang Kesejahteraan Sosial, ayat (1) masyarakat mempunyai kesempatan yang seluasluasnya untuk berperan dalam penyelenggaraan kesejahteraan sosial, ayat (2) peran sebagaimana dimaksud pada ayat (1) dapat dilakukan oleh perseorangan, keluarga, organisasi keagamaan, organisasi sosial kemasyarakatan, lembaga swadaya masyarakat, organisasi profesi, badan usaha, lembaga kesejahteraan sosial dan lembaga kesejahteraan sosial asing, ayat (3) peran sebagaimana dimaksud pada ayat (2) dilakukan untuk mendukung keberhasilan penyelenggaraan kesejahteraan sosial. Didasari hal tersebut maka perlu diadakan pelatihan dan 
pembekalan kepada karang taruna agar menjadi mandiri dan berperan dalam meningkatkan kesejahteraan sosial (Rorong, et al., 2015). Pelatihan ini merupakan salah satu wujud pembekalan kepada pemuda di karang taruna.

Pembekalan tersebut tidak hanya teknologi-teknologi dalam hal pertamanan tetapi juga teknologi-teknologi dibidang perbanyakan tanaman. Diharapkan nantinya pemuda akan mampu memperbanyak dan menediakan tamanan melalui tanaman yanag sudah ada, dan mampu melakuan manajemen serta perawatan tamanan. Taman merupakan elemen penting dalam sebuah hunian. Taman merupakan tempat untuk berkumpul, bermain dan juga berolahraga (Sunoto dan Nulhakim. 2017). Membuat taman tentu saj amembutuhkan biaya yang tidak sedikit. Biaya tersebut berkaitan dengan belanja elemet lunak, element keras ataupun tersebut akan lebih bisa ditekan apabila komponen tanaman hias bisa disediakan secara mandiri. Kemandirian tersebut bisa dilakukan apabila santri dibekali berbagai skill dan ketrampilan dalam hal perbanyakan tanaman hias baik secara vegetatif dan generatif (Yusuf., et. al 2016).

Tujuan dari program pengabdian masyarakat ini adalah 1) Memberikan wawasan baru kepada para pemuda dalam karang taruna tentang perbanyakan tanaman 2) Memberikan wawasan kepada para pemuda dalam karang taruna tentang pembuatan taman 3) Pemuda dalam karang taruna bisa melakukan penyedian bibit tanaman hias dan tanaman buah secara mandiri.

\section{Metode}

Tahapan dalam pelaksanaan program pengabdian kepada masyarakat ini dibagi menjadi pra pelaksanaan dan pelaksanaan. Tahapan prapelaksanaan meliputi : 1) Observasi lapangan. 2) Tahapan persiapan alat dan bahan. Merupakan tahapan persiapan untuk menyiapkan segala persiapan alat dan bahan sebagai bahan praktek pelatihan untuk mitra. Adapun tahapan pelaksaan meliputi 1) Praktek pembuatan verticulture 2) Materi tentang Perbanyakan tanaman hias dengan perbanyakan vegetatif 3) Praktek perbanyakan tanaman buah dengan stek dan cangkok. Kesimpulan dari kegiatan pengabdian masyarakat ini yaitu sudah dapat menyelesaikan permasalahan 1) pemuda dalam karang taruna terampil dalam penyediaan bahan tanam tanaman hias dan buah untuk di tanam di lingkungan 2) pemuda dalam karang taru terampil dalam nembuat vertical garden. Kegiatan observasi dan pelaksanaan dilakukan dengan kordinasi antara fakultas pertanian Universitas Islam Indragiri dan Karang taruna desa pekan kamis dibantu Himaprodi Agroteknonolgi. Kegiatan perbanyakan tanaman dilakukan di laboraturium percobaan prodi agroteknologi fakultas pertanian Universitas Islam Indragiri pada tgl 7 Oktober 2019.

\section{Hasil Dan Pembahasan}

Dari hasil observasi lapangan, diketahui permasalahan dari karang taruna adalah kurangnya skill dalam manajemen pengelolaan dan perawatan taman. Adapun solusi yang ditawarkan untuk penyelesaian masalah adalah 1) Peningkatan kemampuan dalam perbanyakan berbagai jenis tanaman hias dan tanaman buah dengan perbanyakan generatif dan vegetatif 2) Manajemen pengelolaan taman, mulai dari penentuan jadwal perawatan tanaman serta metode perawatan taman yang tepat. Adapun luaran kegiatan ini adalah 1) pemuda terampil melaksanakan budidaya tanaman dengan vegetatif 2) Kemandirian karang taruna dalam penyediaan bibit tanaman hias 3) Pemanfaatan lahan kosong untuk bertanam dilahan sempit.

Materi yang diberikan pada tahapan pertama adalah perbanyakan tanaman secara vegetatif dengan sambung atau grafting. Kegiatan meliputi materi pengenalan tentang program studi Agroteknologi, perbanyakan vegetatif dan grafting (sambung). Dalam pemberian materi tersebut dijelaskan definisi perbanyakan vegetatif, perbedaaan perbanyakan vegetatif dengan generatif, kemudian dijelaskan manfaat dan kekurangan perbanyakan vegetatif. Selain materi tersebut, juga dijelaskan tanaman apa saja yang bisa diperbanyak dengan 
grafting. Untuk memotivasi para santri, juga dijelaskan potensi ekonomi pembibitan tanaman buah.Para peserta tampak antusias dalammengikuti semua rangakaian kegiatan pengabdian kepada masyarakat baik materi ataupun praktek. Semua peserta pelatihan mendapat kesempatan untuk melaksanakan kegiatan praktek grafting tanaman hias.

Dari sebaran angket evaluasi kegiatan diketahui bahwa peserta pelatihan merasa cukup dengan materi yang diberikan, materi yang diberkan cukup jelas meskipun banyak yang menjawab waktu yang diberikan untuk pelatihan sangat kurang. Dari hasil evaluasi diketahui bahwa tanaman grafting yang berhasil tumbuh meskipun hanya 2 tanam. Menurut Roshetko, et.al (2006), bahwa salah satu syarat agar grafting berhasil ialah batang bawah dipilih dari tanaman yang mampu beradaptasi atau tumbuh kompak dengan batang atasnya, kemudian tanaman dalam kondisi sehat dengan sistem perakarannya baik dan dalam serta tahan terhadap keadaan tanah yang kurang menguntungkan, termasuk hama dan penyakit tidak mengurangi kualitas dan kuantitas buah pada tanama yang sudah disambungkan/diokulasi, sedangkan batang atas mempunyai kriteria yang harus mempunyai kemampuan beradaptasi atau tumbuh kompak dengan batang bawahnya, sehingga batang atas ini mampu menyatu dan dapat berproduksi dengan optimal, cabang dari pohon yang sehat, pertumbuhannya normal dan bebas dari serangan hama dan penyakit dan cabang berasal dari pohon induk dengan kualitas tinggi.

Sesi 1 dibagi menjadi dua acara pelatihan, yaitu perbanyakan tanaman hias dengan stek dan pelatihan pertanian lahan sempit dan hidroponik. Menurut Andoko (2004), tujuan utama penerapan teknik vertikultur adalah memanfaatkan lahan sempit seoptimal mungkin. (Apriyanto 2019) menambahkan, vertikultur dapat diterapkan pada daerah-daerah dengan lahan sempit, khususnya di daerah perkotaan yang kini rata-rata menjadi pemukiman yang padat.
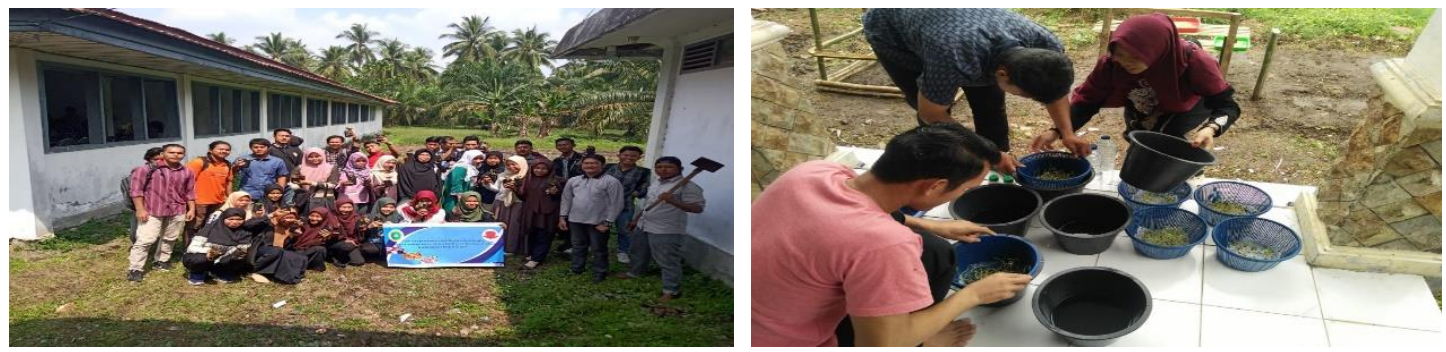

Gambar 1: Peserta, Hima prodi dan Tim pemberi materi sebelum praktek dan Gambar 2. Peserta Praktek menyiapkan media tanam

Kegiatan berikutnya yang dilaksanakan setelah pertanian lahan sempit dengan memanfaatkan bekas drigen (galon). Tanaman hias yang dibudidayakan dengn stek diantaranya Bunga Soka Merah, Soka Kuning dan Soka Putih serta Puring. Perbanyakan tanaman dengan cara setek merupakan perbanyakan tanaman dengan cara menanam bagianbagian tertentu dari tanaman (Roshetko., et el 2006). Bagian tertentu itu bisa berupa pucuk tanaman, akar, atu cabang. Proses penyetekan tanaman itu sendiri cukup mudah, dengan tinggal memotong tanaman yang terpilih dengan menggunakan pisau yang tajam untuk menghasilkan potongan permukaan yang halus. Pemotongan stek bagian ujung sebaiknya berada beberapa milimeter dari mata tunas. Cahyanti dan Hamawi, (2016), menjelaskan bahwa penyediaan bahan tanam asal setek telah demikian populer, karena merupakan cara yang paling cepat untuk memenuhi kebutuhan bahan tanaman (bibit) dalam jumlah banyak.Pertumbuhan setek dipengaruhi oleh ukuran setek. Panjang setek menentukan jumlah cadangan makanan yang terkandung dalam setek.

Pada sesi kedua, dilaksanakan pelatihan pembuatan hidroponik dan tempat tanaman. Tempat tanaman terbuat dari barang bekas seperti galon, drigent, botol dan kemasan gelas sebagai wadah media tanam. Media tanam yang digunakan adalah tanah dan pupuk kandang. Tanaman kemudian ditanam didalam media tersebut.

\section{Simpulan Dan Saran}


Kesimpulan dari kegiatan ini adalah seluruh peserta sudah dapat melakukan pertanian lahan sempit dan perbanyakan tanaman melalui stek. Disarankan agar program semacam ini dapat berlanjut pada mitra

\section{Daftar Rujukan}

Apriyanto, Mulono. 2019. "Pelatihan Dan Pendampingan Pengolahan Komoditas Kelapa." Jurnal Pengabdian Dan Pemberdayaan Masyarakat 3(2): 179-83.

Cahyanti, Lutfy Ditya, and Mahmudah Hamawi. 2016. "IBM Perbanyakan Tanaman Secara Vegetatif Di Pondok Modern.” Jurnal Terapan Abdimas 3(3): 54-59.

Kurniasari, Dewi et al. 2014. "Peranan Organisasi Karang Taruna Dalam MengembangkanKreativitas Generasi Muda Di Desa Ngembalrejo." Unnes Civic Education Journal 2(2): 77-82.

Roidah, Ida Syamsu. 2014. "Pemanfaatan Lahan Dengan Menggunakan Sistem Hidroponik." Jurnal Universitas Tulungagung BONOROWO 1(2): 43-50.

Rorong, Farra Aprilia Kawalod, Arie, and Verry Y. Londa. 2015. "Peranan Organisasi Karang Taruna Dalam Pemberdayaan Masyarakat Desa (Suatu Studi Di Desa Tewasen, Desa Pondos, Desa Elusan, Desa Wakan Kecamatan Amurang Barat Kabupaten Minahasa Selatan)." JAP III(31): 1-10.

Roshetko, James M, Gerhard E S Maurung, and Joel M Tukan. 2006. "Tehnik Pembibitan Dan Perbanyakan Vegetatif Tanaman Buah."

Sunoto, Imam, and Ade Lukman Nulhakim. 2017. "Mengukur Tingkat Partisipasi Pemuda DALAM Program Karang Taruna Dengan Pendekatan Metode Fuzzy Infrence." Jurnal SIMETRIS 8(2): 711-20.

Surtinah. 2018. "Potensi Pekarangan Sempit Untuk Memenuhi Kebutuhan Pangan Keluarga Di Pekanbaru." Jurnal Agribisnis 20(2): 196-205.

Suyadi, Aman, and Bambang Nugroho. 2017. "Pelatihan Memanfaatkan Lahan Sempit Untuk Budidaya Sayuran Organik Training." Jurnal Pengabdian Dan Pemberdayaan Masyarakat 1(2): 95-102.

Yusuf, Ilma Fatimah, Edhi Martono, Agus Prasetya. 2016. "Peran Pemuda Dalam Pengembangan Eduwisata Energi Terbarukan Dan.” Jurnal Ketahanan Nasional 22(3): 285-305. 